\title{
INCONGRUÊNCIAS ENTRE A ATUAL PNA, BNCC E PESQUISAS NA ÁREA DE ALFABETIZAÇÃO NO BRASIL
}

\author{
Suzana Lopes de Albuquerque ${ }^{\text {DD } 1}$ e Amanda de Andrade Costa (D)2
}

\section{Resumo}

A Secretaria de Alfabetização (SeAlf) do Ministério da Educação tem silenciado pesquisas científicas realizadas no âmbito das universidades brasileiras em diferentes níveis de formação de professores a partir da Política Nacional de Alfabetização (PNA).Este artigo objetiva analisar as incongruências na proposta de alfabetização na PNA com a Base Nacional Comum Curricular (BNCC). A Política Nacional de Alfabetização foi criada no ano de 2019 apresentando impactos já no início de 2020 por meio de propagandas midiáticas de programas como Tempo de Aprender (2020), Literacia familiar (2019), dentre outros que se fundamentam nessa política. A PNA apresenta muitas características marcantes, destacando rigorosamente e repetidamente o processo de alfabetização norteado por ciências cognitivas advindas de um contexto internacional com a primazia do método fônico. Na PNA, a literacia emergente e literacia familiar substituem o termo letramento apresentando uma promessa de alterar os resultados negativos nas estatísticas apresentadas no documento sobre o contexto do processo de alfabetização no país. O objetivo desse escrito é apresentar as incongruências, no sentido de contradições, desta política com a proposta de alfabetização e letramento que comparece na Base Nacional Comum Curricular (2018), buscando apresentar que tais incongruências implicam em diferentes concepções de sujeito, homem e sociedade, vislumbrando diferentes projetos de formação desses sujeitos.

Palavras-chave: Alfabetização; PNA; BNCC; Incongruências; Brasil.

\section{INCONGRUENCES BETWEEN THE CURRENT PNA, BNCC AND RESEARCH IN THE LITERACY AREA IN BRAZIL}

\section{Abstract}

The Secretariat for Literacy (SeALF) of the Ministry of Education's has silenced scientific research out within the scope of Brazilian universities at different levels of teacher education based on the National Literacy Policy (PNA). This article aims to analyze the inconsistencies in the literacy proposal in the PNA with the Common National Curricular Base (BNCC). The National Literacy Policy (PNA) was created in 2019 with impacts already in the beginning of 2020 through

\footnotetext{
${ }^{1}$ Professora do Instituto Federal de Educação (IFG - Câmpus Goiânia Oeste). É líder do Grupo de Estudo Panecástica. Email: suzana.albuquerque@ifg.edu.br

${ }^{2}$ Graduada em Pedagogia pelo Instituto Federal de Goiás (IFG). Email: amandinha.andrade10@gmail.com (c) (i) $($ )
}

Perspectivas em Diálogo, Naviraí, v. 08, n. 17, p. 490-505, maio./ago. 2021. 
media advertisements for programs such as "Tempo de Aprender (2020), Literacia familiar (2019), among others that are based on this policy. The PNA has many outstanding characteristics, rigorously highlighting the process of literacy guided by cognitive sciences arising from na international context, with the primacy of the methodological use of the phonic method. In PNA, emerging literacy and familiy literacy replace the term literacy with a promise to change the negative results in the statistics presented in the document on the context of the literacy process in the country. The objective of this writing is to presente the inconsistencies, in the sense of contradictions, of this policy with the literacy and literacy that appears in the Common Base National Curriculum (2018), seeking to present that such incongruities imply diferente conceptions of suject, man and society, envisioning different projects of formations ot these subjects.

Keywords: Literacy; PNA; BNCC; Incongruities; Brazil.

\section{A proposta de alfabetização na Política Nacional de Alfabetização (PNA/SeAlf/2019)}

A Política Nacional de Alfabetização (PNA) foi instituída promulgada pelo Ministério da Educação (MEC) por meio da recém-criada Secretaria de Alfabetização (SeAlf) não foi esboçada com nenhuma consulta de caráter público para que os professores pudessem opinar sobre a sua formulação. Morais (2019) apresenta o caráter antidemocrático da PNA pela ausência de discussão com os pesquisadores brasileiros da área.

O documento da PNA pontua as dificuldades e os inadequados resultados sobre os níveis de leitura, escrita e sobre a matemática no Brasil. A discussão sobre a composição do documento e as finalidades de sua criação pautam-se nas dificuldades existentes no processo de alfabetização nas escolas públicas brasileiras.

O baixo desempenho é demonstrado por meio de estatísticas que apresentam os resultados negativos sobre o nível de leitura e escrita dos alunos através de dados da Avaliação Nacional da Alfabetização (ANA). Tais dados foram extraídos do Instituto Nacional de Estudos e Pesquisas Educacionais Anísio Teixeira (INEP); estando $54,73 \%$ dos alunos com níveis insuficientes de leitura, $33,95 \%$ dos alunos com níveis insuficientes de escrita, e $54,46 \%$ dos alunos em níveis insuficientes de matemática (BRASIL, 2019).

Afim de melhorar estes índices, a PNA apresenta como saída para tais práticas defasadas no ensino da leitura e escrita na PNA, a prescrição de um método sob a base fônica. Ao assumir uma postura prescritiva de parâmetros a serem seguidos, a PNA fundamenta-se em evidências científicas adotando como solução para o mal do analfabetismo a utilização do método fônico como metodologia de ensino.

Ao anunciar uma novidade fundamentada em evidências científicas, a PNA revela a falta de conhecimento histórico sobre a introdução da matriz fônica no 
Brasil ainda no império ${ }^{1}$ brasileiro, deixando explícito o interesse político empresarial na área.

A tentativa de imposição de "pensamento único", por meio do método fônico/instrução fônica e correspondente conceito rudimentar de alfabetização, sintetiza interesses de integrantes de segmentos educacionais e empresariais representados, dentre outros, pelo "painel de especialistas" da CONABE, e atrelados aos interesses políticos, ideológicos e econômicos do governo federal, a exemplo da defesa da "escola sem partido", do ensino domiciliar, das escolas cívico-militares, dos ataques grosseiros e beligerantes às universidades públicas e da imposição da "reforma da previdência" e da "reforma trabalhista" (MORTATTI, 2019, p.29).

O programa Tempo de Aprender (2020) foi criado como desdobramento da PNA e utiliza como recursos avaliativos do nível de leitura dos alunos a leitura em voz alta enquanto uma habilidade para marcação da velocidade e precisão. A redução do processo de alfabetização à essa forma avaliativa é considerada mecânica e restritiva por desconsiderar a perspectiva do letramento e da leitura como prática social, as pesquisas científicas brasileiras que, desde a década de 60 , têm atribuído a função social, psicológica, cultural, política, dentre outras, imbuídas no ato de aprender a ler e escrever e os estudos ABALF.

Ao defender que as políticas públicas para a alfabetização no Brasil não seguem os parâmetros estabelecidos em evidências científicas, a PNA recorre aos estudos das ciências cognitivas, fixando sua proposta em uma dimensão biológica.

É daí que nasce um campo de estudos importantíssimo para o aprofundamento da alfabetização: a ciência cognitiva da leitura, que se ocupa especialmente dos processos linguísticos, cognitivos e cerebrais envolvidos na aprendizagem e no ensino das habilidades de leitura e de escrita e procura responder a perguntas fundamentais: 'Como funciona o cérebro de quem está aprendendo a ler? Algo nele muda? Como aprendemos a ler? (DEHAENE, 2011; SARGIANI; MALUF, 2018 apud BRASIL, 2019, p. 20).

Ao focar na dimensão biológica com um viés da psicologização do processo de alfabetização, a PNA desconsidera as outras nuances que compõe o ato de aprender a ler e escrever. Tal reducionismo é descrito por Morais (2019).

Essa falaciosa acusação nos parece um artifício autoritário, com um evidente interesse de calar quem pensa e pesquisa de modo diferente daquele idolatrado pelos psicólogos cognitivos e neurocientistas que apoiaram e ajudaram a "costurar" essa PNA, apresentada como a única que, supostamente, seria "baseada em evidências científicas" (MORAIS, 2019, p. 71).

${ }^{1}$ Ver ALBUQUERQUE (2019). 
Uma nota de posicionamento da Associação Brasileira de Alfabetização $(A B A L F)^{1}$, frente ao programa Tempo de Aprender - que está fundamentado na PNA -denuncia a desconsideração com o trabalho e estudos de pesquisadores na área da alfabetização no Brasil, haja visto que aderiram às teorias científicas cognitivas proposta por autores estrangeiros, sem abertura ao diálogo com pesquisadores e professores conhecedores da realidade das escolas públicas nacionais, que possuem uma formação acadêmica voltada para o assunto e longa carreira de experiências na alfabetização.

A nota apresenta ainda uma crítica à restrição metodológica do processo de alfabetização pois além de restringir conceitualmente o ato de aprender a ler e escrever a um processo tecnicista de utilização de algum método, ainda prescreve o método fônico como a panaceia para todos os males que englobam a alfabetização. Reduzir o processo de alfabetização a uma marcha sintética de método fônico é desconsiderar todas essas nuances que envolvem a formação de um sujeito completo e que reitera o perigo de uma prática mecanicista esvaída de uma função social.

A PNA substitui a proposta de letramento que vislumbra o uso social da língua, como "estado ou condição de quem não apenas sabe ler e escrever, mas cultiva e exerce as práticas sociais que usam a escrita" (SOARES, 1998, p.47) e adota o termo literacia.

Literacia é o conjunto de conhecimentos, habilidades e atitudes relacionados à leitura e à escrita, bem como sua prática produtiva. Pode compreender vários níveis: desde o mais básico, como o da literacia emergente, até o mais avançado, em que a pessoa que já é capaz de ler e escrever faz uso produtivo, eficiente e frequente dessas capacidades, empregando-as na aquisição, na transmissão e, por vezes, na produção do conhecimento (BRASIL, 2019, p. 21).

Não se trata de uma simples substituição de termos. O conceito de letramento, com uma prática de alfabetização focada no uso social da leitura e escrita, cede lugar à literacia, voltada para as habilidades, para a produtividade, gerando novos conhecimentos, porém, sem compromisso com uma formação social dentro da perspectiva de produção de conhecimentos.

Com isso, a PNA impõe uma proposta de alfabetização desvinculada do letramento, como se fosse possível. A PNA prioriza um método de ensino fônico sem a abertura para as práticas de letramento desconsiderando as interações dos sujeitos com a cultura escrita em contextos específicos escolares e extraescolares, como afirma Bunzen (2019):

Não é possível mais conceber um processo de escolarização em massa no século XXI que planeje suas ações pedagógicas negligenciando 0 uso da escrita nos contextos heterogêneos, interculturais e complexos os quais envolvem várias crianças, suas

Fonte: http://abalf.org.br/?page_id $=69$ 
redes familiares e comunidades. Desta forma, o estudo sobre as diversas práticas de letramento e das interações dos sujeitos com a cultura escrita em contextos específicos escolares e extraescolares auxiliam as alfabetizadoras, ampliando tais práticas e promovendo eventos de letramento significativos (BUNZEN, 2019, p. 46).

Diante da afirmação de Bunzen (2019), pode-se perceber de uma maneira mais rigorosa o motivo da PNA não trazer a discussão do letramento: sua opção pelo viés tecnicista da adoção de uma única via metodológica excluindo as demais nuances que compõem o processo de alfabetização. A exclusão do letramento, parte importante no processo de formação social do indivíduo, reforça a intencionalidade de uma limitação metodológica do processo de alfabetização.

A PNA foi escrita por uma equipe de especialistas com formação acadêmica, sendo 13 da área de Psicologia, dois da área de Linguística, e cinco da Educação. Segundo Maciel (2019), de vinte e um colaboradores, treze são brasileiros, sendo apenas um da área da educação com formação em Pedagogia. Segundo Morais (2019), os autores da PNA, ligados diretamente ao governo, forma um grupo que desde 2003 demonstravam interesse na adesão ao método fônico na alfabetização no Brasil.

Torna-se imprescindível refletir sobre a forma simplista que o documento apresenta caminhos metodológicos para a melhoria do rendimento dos alunos na alfabetização, como se fosse uma solução prática e muito revolucionária, problematizando as intenções motivadoras dessa concepção de educação tecnicista que comparece no documento.

Ao colocar um ponto final nesse texto, lembramos aos colegas docentes de IES que apoiaram e apoiam a PNA que o governo que quer impor aquela proposta é o mesmo que avança na privatização de universidades, que tem destruído os investimentos em ciência e tecnologia e que defende a militarização das escolas como salvação da educação brasileira (MORAIS, 2019, p.74).

Dessa forma, é necessário problematizar as intenções motivadoras dessa política, que escancara a falta de diálogo com a educação brasileira pública, com os professores, pesquisadores e com as produções locais acerca da temática da alfabetização, desvalorizando, inclusive os saberes e experiências de quem conhece e sabe das dificuldades existentes nas salas de aulas por todo o país.

\section{A proposta de alfabetização e letramento na Base Nacional Comum Curricular (BNCC/2018)}

A criação da Base Nacional Comum Curricular (BNCC) estava prevista na Lei de Diretrizes e Bases da Educação de 1996. 
Os currículos da educação infantil, do ensino fundamental e do ensino médio devem ter base nacional comum, a ser complementada, em cada sistema de ensino e em cada estabelecimento escolar, por uma parte diversificada, exigida pelas características regionais e locais da sociedade, da cultura, da economia e dos educandos (BRASIL, 1996, art.26).

A elaboração da BNCC iniciou-se em 2015 e teve abertura para a consulta pública, sendo implantada em 2018, consistindo em uma tentativa de padronização do currículo a ser aplicado, no âmbito das escolas públicas e privadas de diferentes regiões brasileiras.

A Base Nacional Comum Curricular (BNCC) foi aprovada pelo CNE em 15 de dezembro de 2017 e homologada pelo Ministro do Estado da Educação Mendonça Filho no dia 20 de dezembro de 2017. Com 20 votos favoráveis e três contrários, a BNCC, segundo divulgado pela grande mídia nacional, servirá de parâmetro para a construção dos currículos pelas escolas da rede de ensino dos estados e municípios.138 Trazendo em destaque no texto o nome do Ministro de Estado da Educação Mendonça Filho, na Secretaria Executiva Maria Helena Guimarães de Castro e na Secretaria de Educação Básica Rossieli Soares da Silva, a versão homologada da BNCC continua com o slogan apresentado na versão anterior "Educação é a base" (TRICHES, 2018, p. 137-138).

Dentre inúmeras críticas recebidas como essa tentativa de engessamento das práticas escolares, Teixeira e Martins (2019) criticam a defesa das ideias de habilidades e competências que comparecem no documento visando uma formação individual restritiva para o mercado de trabalho e não para a formação social.

Em 2015 surgiu a primeira versão da BNCC e foi disponibilizada pelo Ministério de Educação (MEC) para consulta pública, com a finalidade de ouvir a opinião da sociedade em geral sobre sua formulação para posterior implantação no ano de 2018. Triches (2018) apresenta uma análise da trajetória dos marcos legais no processo de elaboração do currículo da Educação Básica brasileira e os movimentos em prol de estabelecer uma Base Nacional Comum Curricular e aborda, também, os posicionamentos de diferentes segmentos da sociedade em relação ao processo (re) construção de um currículo comum para a Educação Básica.

Enquanto o MEC "dá voz" a um segmento da sociedade, outros segmentos/entidades como ANPAE, ANPED e FINEDUCA se manifestavam publicamente por meio de debates, cartas, argumentações diversas no sentido de apontar a necessidade de ampliação das discussões acerca da implementação de uma Base comum para os currículos, como também das concepções que vinham sendo desenhadas nas diferentes versões apresentadas à sociedade. Dentre as manifestações, estava a campanha "Aqui já tem Currículo: o que criamos na escola...", movimentada pela ANPED, por meio das redes sociais, com o intuito de conscientizar 
a sociedade e sensibilizar o MEC no sentido de que as escolas já têm seus currículos definidos, orientados pelos PCNs, DCNs e matrizes curriculares dos respectivos estados e municípios (TRICHES, 2018, p. 144).

A intenção de criar uma base comum para padronizar o ensino em todo o país, principalmente no que diz respeito à organização e estrutura, não pode silenciar a denúncia de que "currículo nacional não vai melhorar a educação nem garantir desenvolvimento e melhor distribuição de renda", devendo ficar claro que ele oferece "apenas a tentativa de controle do imponderável da qual depende, não o sucesso da educação, mas a hegemonia do imaginário neoliberal de que ele é parte" (MACEDO, 2014, p.24).

Nesses termos, políticas são engendradas a partir da hegemonia das forças neoliberais, de tal maneira que, não apenas as relações de convivência educativa escolar, mas a vida cotidiana dos indivíduos passa a ser gerenciada pela concepção neoliberal de mundo. Dentro dessa tendência as pessoas passam a ser vistas como produtos secundários de um estilo de vida no qual o ter se sobrepõe ao ser. Essa tendência tenta reduzir os seres humanos a tornarem-se meros consumidores do que é imposto por um sistema que acaba possuindo-os (TRICHES, 2019, p. 147).

Frade (2020) afirma que desde a abertura para as consultas públicas sobre o documento, a parte que se refere à alfabetização e língua portuguesa foram as áreas que mais receberam comentários entre setembro de 2015 e março de 2016. A BNCC explicita novas regras para a alfabetização, que deve ser o foco dos dois primeiros anos do Ensino Fundamental, para que "os alunos se apropriem do sistema de escrita alfabética de modo articulado ao desenvolvimento de outras habilidades de leitura e de escrita e ao seu envolvimento em práticas diversificadas de letramento" (BRASIL, 2018, p. 59).

A BNCC reduz o tempo do processo de alfabetização de três para os dois anos iniciais no ensino fundamental-anos, ficando o terceiro ano reservado exclusivamente para aprender a ortografia da língua portuguesa escrita. Essa redução torna-se problemática quando impõe um tempo de aprendizado para o aluno, desconsiderando o aprendizado prévio e várias facetas da alfabetização sinalizadas por importantes pesquisas feitas por autores que avançaram nas didáticas metodológicas.

A contradição se evidencia nesse trecho haja vista que, ao tratar da questão curricular, o texto da BNCC enaltece a valorização do respeito às diferenças apresentadas por cada comunidade, cada escola, cada aluno, entretanto esse valor não é respeitado no Documento. Isso pode ser certificado no alijamento da opção de escolha da Língua Estrangeira e no estabelecimento da Língua Inglesa como obrigatória, na retirada da Língua Materna para 145 populações indígenas, como também na alteração do tempo destinado ao processo de alfabetização da criança, sendo que, conforme dispunha a terceira versão do documento: "nos dois 
primeiros anos do Ensino Fundamental, a ação pedagógica deve ter como foco a alfabetização [...]" (BRASIL, MEC, BNCC, 2017) e novamente reiterada na versão aprovada, "o processo de alfabetização deverá ocorrer nos dois primeiros anos do Ensino Fundamental" (TRICHES, 2018, p. 144-145).

Segundo Teixeira e Martins (2019), "é necessário um olhar mais atento sobre as mudanças relacionadas à alfabetização, para que não a torne uma etapa acelerada por interesses que não condizem com os contextos das escolas e com as possibilidades de aprendizagem das crianças" (TEIXEIRA; MARTINS, 2019, p. 6).

Outrossim, reitera a ênfase nas de habilidades do aluno, característica rigorosa que está presente ao longo do conceito e parâmetros sobre a alfabetização e língua portuguesa. Para a BNCC, alfabetizar é:

[...] trabalhar com a apropriação pelo aluno da ortografia do português do Brasil escrito, compreendendo como se dá este processo (longo) de construção de um conjunto de conhecimentos sobre o funcionamento fonológico da língua pelo estudante. Para isso, é preciso conhecer as relações fono-ortográficas, isto é, as relações entre sons (fonemas) do português oral do Brasil em suas variedades e as letras (grafemas) do português brasileiro escrito (BRASIL, 2020, p. 90).

A BNCC orienta o processo de alfabetização sob o prisma da capacidade da criança de codificar ou decodificar os sons da língua em material gráfico, restringindo o processo à capacidade de relacionar grafemas e fonemas, excluindo todas as outras características que marcam todo o contexto e que refletem diretamente na qualidade de educação e formação dos sujeitos.

Segundo Soares (2003), ensinar a ler e a escrever extrapola as relações entre fonemas e grafemas, pois envolve o uso social dessa escrita a partir de práticas de letramento. O termo letramento aparece no texto preliminar da BNCC (2018).

Nos dois primeiros anos do Ensino Fundamental, a ação pedagógica deve ter como foco a alfabetização, a fim de garantir amplas oportunidades para que os alunos se apropriem do sistema de escrita alfabética de modo articulado ao desenvolvimento de outras habilidades de leitura e de escrita e ao seu envolvimento em práticas diversificadas de letramentos (BRASIL, 2018, p. 59).

Apesar de trazer a questão do letramento, a BNCC apresenta sua composição focada nas competências e habilidades do aluno, com a possibilidade, dentro de uma leitura equivocada, de oferecer uma educação prática e tecnicista. 


\section{Incongruências nas concepções teóricas e metodológicas na PNA e BNCC acerca do processo de alfabetização}

A PNA explicita seu viés tecnicista ao desconsiderar uma preocupação com as práticas e usos sociais da língua, ao retomar um caminho metodológico da marcha sintética e fonética e excluir a proposta de letramento e de pesquisas de professores e pesquisadores brasileiros vinculados ao processo de alfabetização.

Mas há divergências, no sentido de os proponentes da PNA terem sido ainda mais autoritários, impondo o método fônico, querendo varrer da história recente da alfabetização brasileira o letramento, o cuidado de alfabetizar ao mesmo tempo em que se ampliam as práticas de leitura e escrita. Os preconceitos descabidos com o construtivismo e com o letramento, ao lado da sectária visão de que só estudos experimentais podem dizer como devemos alfabetizar, são obra dos autores da PNA que, como já dissemos, adotavam esse discurso desde 2003 (MORAIS, 2019, p. 67).

Várias perguntas são lançadas: como o documento poderia citar novas formas de alfabetizar uma criança, desvalorizando todas as conquistas de cunho intelectual do processo que já existe? Ainda, sem a presença de professores alfabetizadores, sem os autores brasileiros que pesquisam e atuam na área com muitos anos de experiência, conhecendo as dificuldades que os professores brasileiros enfrentam na sala de aula?

Ela, a PNA, não quer que o professor seja um agente pensante, que decide sobre como alfabetizar seus alunos, buscando ajustar-se às necessidades e interesses de cada menino e de cada menina. Portanto, desrespeita, completamente, os saberes profissionais e experiências dos alfabetizadores (MORAIS, 2019, p. 74).

A PNA não traz tantas inovações como a propaganda do MEC divulga na rede aberta de televisão. Já no início do documento, apresenta-se a razão da criação da política ter sido criada: baixo desempenho dos estudantes que sabem ler e escrever. Em nenhum momento, a PNA problematiza as razões de esse número ser consideravelmente negativo, evocando questões como as desigualdades sociais existentes, as condições precárias das escolas públicas, escassos investimentos, dentre outras. Ao tentar impor sua política, ignora essas dificuldades para uma efetivação do processo de alfabetização.

Diante da adoção desse método, podemos visualizar um viés político, que fica implícito dentre um projeto de nação. Segundo Mortatti (2019) essa imposição é exigida por interesses políticos, ideológicos e econômicos do governo federal, sendo que a adoção deste método relacionada com a ideia de que ele é novo, validando por isso seu uso, oculta os motivos reais culpados pelas falhas no processo de alfabetização, conectados com os fatores educacionais, sociais, econômicos, políticos, responsáveis pelas desigualdades sociais. 
Assim, ainda de acordo com a autora, o método fônico foi adotado com a falsa premissa de que é uma solução nova e científica para os problemas atuais no Brasil, porém existem pesquisas científicas que comprovam que ele não é novo na história da alfabetização no país, como a tese de Albuquerque (2019) que retrata a introdução do método fônico de Castilho no império brasileiro, em 1855.

Sendo assim, os conceitos do método fônico apresentados na PNA não favorecem o processo de letramento discutido no documento. A exclusão do termo letramento da PNA nos permite enxergar uma intenção que pode estar implícita: a formação técnica dos sujeitos. Essa forma de conceber o processo formativo dos estudantes está vinculada diretamente aos autores da PNA, que em sua maioria é composta por grandes empresários (MORAIS, 2019).

Bunzen (2019) considera bastante desrespeitosa e impositiva a eliminação do conceito de letramento da PNA e suas diversas implicações para o campo da alfabetização.

Se na BNCC para Educação Infantil e Ensino Fundamental, a palavra é utilizada 48 vezes; na PNA, a palavra nem é mencionada. Existe um total apagamento do conceito e de seus desdobramentos, diferenciando-se fortemente da BNCC que mobiliza conceitos mais contemporâneos como "novos letramentos" ou "multiletramentos". Tal silenciamento não é neutro e, certamente, faz parte de uma estratégia discursiva maior de apagamento de mais um campo do conhecimento e de discussões sobre alfabetização no Brasil. Pela grande influência que tais estudos tiveram no Brasil nos últimos trinta anos e por ser um conceito guarda-chuva de várias políticas do próprio Ministério da Educação nos últimos vinte anos (pensando aqui desde a publicação dos PCNs até a BNCC), faz-se necessário pensar o porquê do arquivamento de tais discursos e implicações pedagógicas (BUNZEN, 2019, p. 46 e 47).

A PNA desconsidera as diferenças que existem dentro de uma sala de aula e a heterogeneidade nos contextos familiares, sociais, culturais e econômicos, dentre outros, eliminando o letramento do processo de alfabetização. No lugar de letramento, temos o conceito de literacia, conforme afirma Bunzen (2019):

No lugar do conceito de "letramento", o documento da PNA procura 'inovar' com a importação europeia de um outro termo, comum em alguns documentos curriculares em Portugal: "literacia". Tal provocação parece-me uma estratégia bastante inadequada, pois pressupõe introduzir no discurso oficial pedagógico um conceito não utilizado no Brasil como se fosse uma "novidade" ou um "termo mais neutro ou técnico" para se referir aos usos da escrita. Há uma tentativa clara de afastamento das políticas públicas de alfabetização anteriores (tais como o Pró-Letramento ou PNAIC), operando ainda com uma retórica infeliz de "internacionalizar" a discussão. Como alguns documentos curriculares portugueses, a PNA opta por usar "literacia", mas não explicita as tensões, 
incoerências e reduções que perpassam tal processo de apropriação curricular. A palavra "literacia" é mencionada 73 vezes no documento (BUNZEN, 2019, p. 47).

A PNA é criada com intenção de alterar o quadro de resultados negativos da alfabetização, mas como vimos sobre a eliminação do letramento, ela não demonstra preocupação com oferecer condições de acesso ao mundo da escrita a todos, através das práticas do letramento. Segundo Morais (2019),

Ao lado do pobre viés teórico que não incorpora uma análise dos textos escritos como gêneros textuais, a que já fizemos menção, 0 texto da PNA também não atenta para a importância fundamental de ampliar as práticas de letramento e as reflexões sobre os usos dos textos e suportes desde a Educação Infantil como uma medida de democratização do acesso ao mundo da escrita. O caderno da PNA nunca leva em conta o fato de que a introdução precoce de práticas letradas, na escola, num país em que o acesso ao mundo da escrita é tão desigualmente assegurado, é uma opção política por democratização, por redução de desigualdades, que só faz bem para os meninos e para as meninas que frequentam nossas redes públicas (MORAIS, 2019, p. 70).

Sendo assim, de um lado, a PNA prioriza uma formação totalmente técnica para os alunos, partindo do pressuposto que somente sabendo ler, os resultados avançariam positivamente. De outro, impõe um documento com nenhuma participação de um dos protagonistas da sala de aula: o professor. Segundo Morais (2019):

Ela, a PNA, não quer que o professor seja um agente pensante, que decide sobre como alfabetizar seus alunos, buscando ajustar-se às necessidades e interesses de cada menino e de cada menina. Portanto, desrespeita, completamente, os saberes profissionais e experiências dos alfabetizadores. Quanto às crianças, os pacotes vendidos pelos mercadores de métodos fônicos tratam a todas de maneira homogeneizante, desconsiderando a diversidade de níveis de conhecimento que os aprendizes, necessariamente, apresentam e vão continuar apresentando (MORAIS, 2019, p. 74).

Enquanto documento orientador dos currículos das escolas de Educação Básica, a normativa da BNCC, apesar de trazer o termo letramento associado ao processo de alfabetização, impõe a alfabetização completa dos estudantes em 2 anos do ensino fundamental - anos iniciais em um movimento de ascensão de métodos tecnicistas.

Foi possível depreender também, nesse movimento de (re) formular o Documento, uma ascensão aos métodos tecnicistas, ou seja, conforme as versões iam sendo apresentadas, essa tendência se intensificava. Na segunda versão o destaque à centralidade da escrita alfabética e das normas ortográficas, na terceira versão a substituição de terminologias como "direitos de aprendizagem" por 
"competências", na versão homologada, a retomada do significante

"decodificar" (TRICHES, 2019, p. 146).

Gontijo (2015) comenta sobre a ausência do caráter político da alfabetização na BNCC. A preocupação primordial era com a instrumentalização técnica dos sujeitos para atenderem as demandas sociais e profissionais exigidas pela sociedade. A BNCC ainda tem sua base voltada para a aprendizagem do aluno, e não se comenta nada a respeito do ensino. Gontijo (2015) nos diz:

É interessante notar que a BNCC propõe objetivos de aprendizagem para cada um dos componentes curriculares que integram as áreas. No que diz respeito à ênfase na aprendizagem, que pode ser inferida dessa denominação, entendemos que é difícil pensar em alcance de objetivos de aprendizagem separados do ensino. A aprendizagem não é algo que se desenvolve sem o concurso de uma mediação qualificada por parte dos docentes (GONTIJO, 2015, p.188).

Teixeira e Martins (2019) anunciam as intenções explícitas com a implantação da BNCC, em 2018.

Com a homologação, o documento anseia "padronizar" o ensino em todo o país. Com isso há a necessidade de reorganização dos currículos escolares em todo o Brasil. Os principais aspectos que o documento dispõe para que os seus objetivos sejam alcançados referem-se às Competências, Habilidades e Direitos de Aprendizagem. Entretanto Marsiglia et al (2017) argumenta que ao enfatizar as "habilidades", as "competências", os "procedimentos" e a "formação de atitudes", e não destacar os conteúdos escolares, o trabalho educativo e o ensinar, o documento apresenta uma perspectiva que visa adaptar os alunos ao mercado de trabalho ou, mais propriamente, ao "empreendedorismo". Ou seja, com o crescente desemprego e a consequente diminuição do trabalho formal, o objetivo dessa formação é preparar os filhos da classe trabalhadora para o mundo do trabalho informal e precarizado, compatível com as novas demandas do capital para este século, voltadas para a acumulação "flexível" (TEIXEIRA; MARTINS, 2019, p. 3-4.).

Sendo assim, é perceptível o caráter também tecnicista da BNCC, focando mais em habilidades e competências do que na formação social dos indivíduos. Segundo Bortolanza, Goulart e Cabral (2018)

Nesse cenário neoliberal, em que tudo se transforma em lucro e mercadoria, a concepção de currículo na BNCC apresenta uma visão estreita e tecnicista trazendo os conhecimentos fragmentados sob a aparência de uma suposta neutralidade" (BORTOLANZA; GOULART; CABRAL, 2018, p. 962). 
A BNCC prioriza uma formação restritiva do processo de alfabetização, porém apresenta a proposta do letramento na formação social dos sujeitos. O comparecimento do termo letramento é uma esperança de possibilidades para uma formação social que leva em consideração vivências, culturas e saberes que circulam no cotidiano dos estudantes. Em seu contexto, também são consideradas as variações linguísticas regionais/nacionais na questão da alfabetização, visto que reflete diretamente na formação social daquele estudante.

Sendo assim, por mais que exista um caráter tecnicista na BNCC, priorizando habilidades e competências, segundo Gontijo (2015), a importância que o documento frisa sobre o respeito e relevância aos contextos culturais dos alunos permite uma formação além dos parâmetros técnicos. Ao apresentar a definição de letramento, a BNCC possibilita o debate sobre a formação social dos sujeitos, em uma perspectiva mais ampla do letramento.

Assim, alfabetizar é trabalhar com a apropriação pelo aluno da ortografia do português do Brasil escrito, compreendendo como se dá este processo (longo) de construção de um conjunto de conhecimentos sobre o funcionamento fonológico da língua pelo estudante. Para isso, é preciso conhecer as relações fonoortográficas, isto é, as relações entre sons (fonemas) do português oral do Brasil em suas variedades e as letras (grafemas) do português brasileiro escrito. Dito de outro modo, conhecer a "mecânica" ou o funcionamento da escrita alfabética para ler e escrever significa, principalmente, perceber as relações bastante complexas que se estabelecem entre os sons da fala (fonemas) e as letras da escrita (grafemas), o que envolve consciência fonológica da linguagem: perceber seus sons, como se separam e se juntam em novas palavras etc. Ocorre que essas relações não são tão simples quanto as cartilhas ou livros de alfabetização fazem parecer. Não há uma regularidade nessas relações e elas são construídas por convenção. Não há, como diria Saussure, "motivação" nessas relações, ou seja, diferente dos desenhos, as letras da escrita não representam propriedades concretas desses sons (BRASIL, 2018, p. 90).

A leitura é tomada na BNCC em um sentido mais amplo, não restrito ao caráter do texto escrito, mas associado a "imagens estáticas (foto, pintura, desenho, esquema, gráfico, diagrama) ou em movimento (filmes, vídeos etc.) e ao som (música), que acompanha e cossignifica em muitos gêneros digitais" (BRASIL, 2018, p.72); urge que tal concepção esteja atrelada no processo de alfabetização e que sua concepção e metodologia não fiquem restritas às relações grafemas-fonemas.

\section{Considerações finais}

Ao analisar sobre a concepção de alfabetização que comparece nos documentos da PNA e da BNCC observa-se incongruências. A PNA anula a questão do letramento no processo de alfabetização e adota o simplismo de (c) (1)

Perspectivas em Diálogo, Naviraí, v. 08, n. 17, p. 490-505, maio./ago. 2021. 
tentar padronizar a questão metodológica da adoção do método fônico como saída para o mal do analfabetismo, enquanto a BNCC, apresenta o termo letramento, porém em um viés instrumentalizador.

Apesar de haver a possibilidade de letramento na BNCC, observa-se um simplismo na concepção de alfabetização ao vincular à questão das competências e habilidades de associação entre grafemas e fonemas, ao reduzir o tempo do processo de alfabetização de três para os dois anos iniciais no ensino fundamental-anos e ao projetar uma ascensão aos métodos tecnicistas, com destaque à centralidade da escrita alfabética e das normas ortográficas, e na substituição de terminologias como "direitos de aprendizagem" por "competências".

Tais retrocessos históricos latentes nestes documentos têm retornado o discurso simplista de adotar um método prescritivo como saída para o mal do analfabetismo do país, mostrando um desconhecimento acerca da história da alfabetização no país, com um discurso já adotado há 160 anos, com a circulação do método fônico de Castilho no Brasil, por exemplo.

Mais do que nunca, é imprescindível abordar as políticas públicas para a alfabetização em um momento histórico de tentativas de redução de seu caráter social para querelas de disputas metodológicas.

\section{REFERÊNCIAS}

ABALF. Posicionamento da ABAlf frente ao Programa de Alfabetização "Tempo de Aprender". Universidade do Estado de Santa Catarina: Florianópolis, 2020.

ALBUQUERQUE, Suzana Lopes de. Métodos de ensino de leitura no Império brasileiro: António Feliciano de Castilho e Joseph Jacotot. 2019. 240f. Tese (Doutorado em Educação) - Faculdade de Educação. Universidade de São Paulo, USP, 2019.

BOTO, Carlota; ALBUQUERQUE, Suzana Lopes de. Entre idas e vindas: vicissitudes do método Castilho no Brasil do século XIX. História da educação (on-line). Porto Alegre, v.22 n.56, set.-dez. 2018. p. 16-37.

BRASIL. Presidência da República. Lei n.o 9.394, de 20 de dezembro de 1996. Estabelece as diretrizes e bases da educação nacional. Brasília: 20 de dezembro de 1996. Disponível em: www.planalto.gov.br/ccivil_03/LEIS/19394.htm Acesso em: 17 dez. 2020.

BRASIL. Ministério da Educação. Base Nacional Comum Curricular. MEC, Brasília, 2018, p.1-113.

BRASIL. Ministério da Educação. Política Nacional de Alfabetização. MEC, Brasília, 2019. 
BRASIL. Ministério da Educação. Tempo de Aprender. Formação continuada em práticas de alfabetização. Secretaria da Alfabetização. Brasília: MEC, SEALF, 2020.

BUNZEN, Clecio. Um breve decálogo sobre o conceito de "literacia na política nacional de alfabetização (PNA, 2019). Revista Brasileira de Alfabetização - ABAlf, Belo Horizonte, MG, v. 1, n. 10 (Edição Especial), p. 44$51,2019$.

BORTOLANZA, Ana Maria Esteves. GOULART, Ilsa do Carmo Vieira. CABRAL, Giovanna Rodrigues. Diferentes perspectivas de alfabetização a partir da Base Nacional Comum Curricular: concepções e desafios. Ensino Em Re Vista, Uberlândia, MG, v.25, n. Especial, p. 958-983, 2018.

CARVALHO, Marlene. Alfabetizar e letrar: um diálogo entre a teoria e prática. Petrópolis, RJ,2005.

CARVAlHO, Marlene. Guia Prático do Alfabetizador. 2a ed. São Paulo: Ática S.A., 1995. $95 p$

FRADE, Isabel Cristina Alves da Silva. Palavra aberta- BNCC e a alfabetização em duas versões: concepções e desafios. Educação em Revista, Belo Horizonte, Dossiê Alfabetização e Letramento no Campo Educacional, v.36, 2020.

GONTIJO, Cláudia Maria Mendes. ANTUNES, Janaína Silva Costa. Diálogos com o plano nacional de alfabetização (2019): contrapalavras. Revista Brasileira de Alfabetização - ABAlf Belo Horizonte, MG, v. 1, n. 10 (Edição Especial), p. 32-38, 2019.

GONTIJO, Cláudia Maria Mendes. Base Nacional Comum Curricular (BNCC): comentários críticos. Revista Brasileira de Alfabetização, Vitória, v. 1, n. 2, p. 174190, jul./dez. 2015.

LEAL, Telma Ferraz. Apontamentos sobre a política nacional de alfabetização 2019. Revista Brasileira de Alfabetização - ABAlf, Belo Horizonte, MG, v. 1, n. 10 (Edição Especial), p. 76-85, 2019.

MACEDO, Elizabeth. Base Nacional Curricular Comum: novas formas de sociabilidade produzindo sentidos para educação. Revista e-Curriculum, São Paulo, v. 12, n. 03 p.1530 - 1555 out./dez. 2014.

MACIEL, Francisca Izabel Pereira. Onde estão as pesquisas sobre alfabetização no Brasil? Revista Brasileira de Alfabetização - ABAlf, Belo Horizonte, MG, v. 1, n. 10 (Edição Especial), p. 58-59, 2019. 
MENDONÇA, Onaide Schwarts. O percurso histórico dos métodos de alfabetização. Faculdade de Ciências e Tecnologia - Departamento de Educação UNESP/ Presidente Prudente, 2011.

MONTEIRO, Sara Mourão. A concepção de alfabetização na Política Nacional de Alfabetização/MEC/2019. Revista Brasileira de Alfabetização - ABAlf , Belo Horizonte, MG, v. 1, n. 10 (Edição Especial), p. 39-43, 2019.

MORAIS, Artur Gomes de. Análise crítica da PNA (Política Nacional de Alfabetização) imposta pelo MEC através de decreto em 2019. Revista Brasileira de Alfabetização - ABAlf, Belo Horizonte, MG, v. 1, n. 10 (Edição Especial), p. 66-75, 2019.

MORTATTI, Maria do Rosário Longo. História dos métodos de alfabetização no Brasil. Abr. 2006.

MORTATTI, Maria do Rosário Longo. Essa base nacional comum curricular: mais uma tragédia brasileira? Revista Brasileira de Alfabetização, v. 1, n. 2, p. 191-205, 2015.

MORTATTI, Maria do Rosário Longo. A "Política Nacional de Alfabetização" (Brasil,2019): uma "guinada" (ideo) metodológica para trás e pela direita. Revista Brasileira de Alfabetização - ABAlf, Belo Horizonte, MG, v. 1, n. 10 (Edição Especial), p. 26-31, 2019.

SOARES, Magda. Letramento e alfabetização: as muitas facetas. Universidade Federal de Minas Gerais, Centro de Alfabetização, Leitura e Escrita. Revista Brasileira de Educação, 2003.

SOARES, Magda. Letramento: um tema em três gêneros. Belo Horizonte: Autêntica, 1998.

TEIXEIRA, Zildiane Souza. MARTINS, Kézia Siméia Barbosa da Silva. Base nacional comum curricular (BNCC) e o processo de alfabetização e letramento da criança: impactos para a escola de ensino fundamental em Parintins, AM. Fortaleza - CE: VI Congresso Nacional de Educação (CONEDU), 2019.

TRICHES, Eliane de Fátima. A formulação da Base Nacional Comum Curricular (BNCC) e concepções em disputa sobre o processo alfabetizador da criança (2015-2017). 2018. 162. Dissertação (Mestrado em Educação). Universidade Federal da Grande Dourados - Dourados, MS: UFGD, 2018. 